\title{
Yield Response and Competition Ability of Italian Ryegrass, Red Clover and Their Mixture to Different Technological Conditions
}

\author{
Vasile IUGA, Ioan ROTAR*, Anamaria MĂLINAŞ, Gheorghe TOTH \\ Department of Plant culture, Faculty of Agriculture University of Agricultural Sciences and \\ Veterinary Medicine \\ 3-5 Calea Manastur, Cluj-Napoca, Romania \\ *corresponding author, e-mail: rotarioan52@yahoo.fr \\ Bulletin USAMV series Agriculture 75(1)/2018 \\ Print ISSN 1843-5246; Electronic ISSN 1843-5386 \\ DOI 10.15835/buasvmcn-agr: 002317
}

\begin{abstract}
The effect of different technological conditions on forage yield, growth behavior and competition ability of ryegrass, red clover and their mixture was analyzed. The results showed that red clover makes better use of the nutrition space in the case of variants sown in mixture with Italian ryegrass than in the monoculture, independent of the density of the plants or fertilization regime. The highest DM production was obtained at the mixture formed by red clover and Italian ryegrass on the variants sown on $12.5 \mathrm{~cm}$ distance between rows, the increase of the nutrition space being directly proportional to the decrease of the DM production in the case of this forage mixture.
\end{abstract}

Keywords: competition, grass mixture, Italian ryegrass, red clover, productivity.

\section{Introduction}

The selections criteria for mixed perennial grasses and legumes are not only ecological criteria, but sometimes economic considerations are also taken into account (Le Gall and Guernion, 2004). Due to this, in order to maintain a balance of forage mixtures, it is advisable to know as much as possible about the requirements of each species, as well as the correlations taking place between populations of different species (Păcurar et al., 2016). One should take into consideration this aspects since mixtures of grasses and legumes are advantageous only in cases where the populations of the species constituting the mixture are maintained at a high level of dynamic equilibrium, provided in principle by interference and competition relations (Hamdollah et al., 2009).

Red clover and Italian ryegrass are two herbaceous perennial often cultivated in Romania. Spatial variation in red clover stand could be due to moisture and light competition effects with the other forage species is sown with. Precipitation and soil moisture levels were observed to influence establishment of small seeded legumes (Keeling et al., 1996). Drought conditions impede establishment and biomass accumulation. Feeding space, in addition to nutrient competition, can reduce biomass of under seeded forage species that are planted simultaneously with red clover (Vidican et al., 2006).

Contrary results pointing to the isolated importance of different driving mechanisms for swards formation, i.e. nutrients, feeding space and competition remain unclear about the respective strengths and relations of these drivers to one another (Archibald, 2008; Finn et al., 2005).

\section{Materials and methods}

The current study has been carried out on 2016 and 2017 experimental seasons. The experiences were installed in Chinteni commune, Cluj County, 


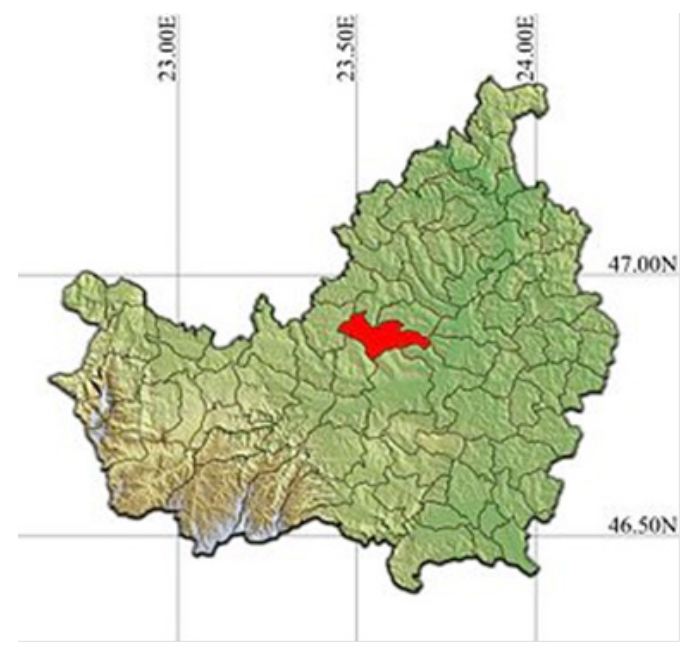

Figure 1. Experimental plot placement

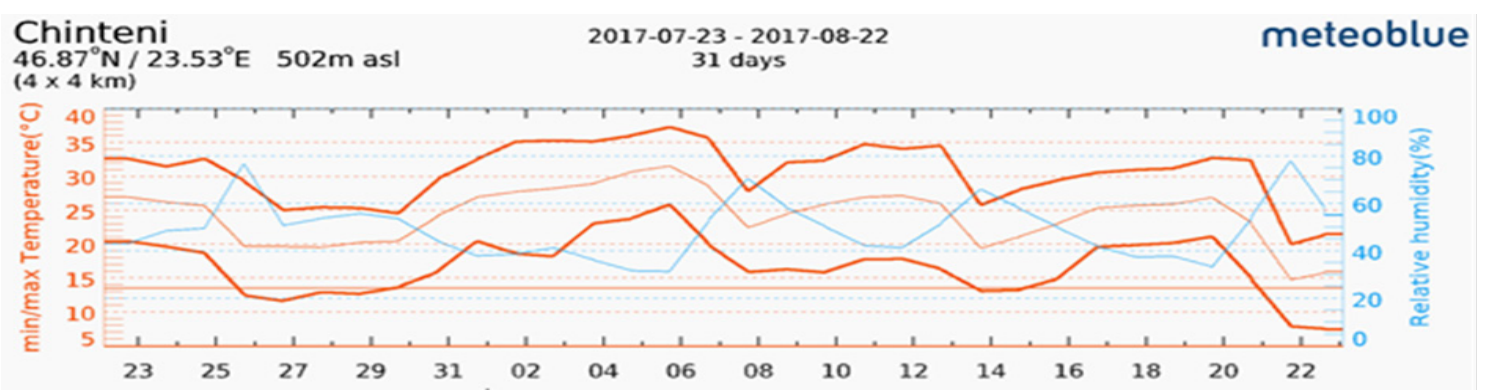

Figure 2. Temperature recorded in Chinteni in the year 2017 (Dec. 2016-Aug. 2017)

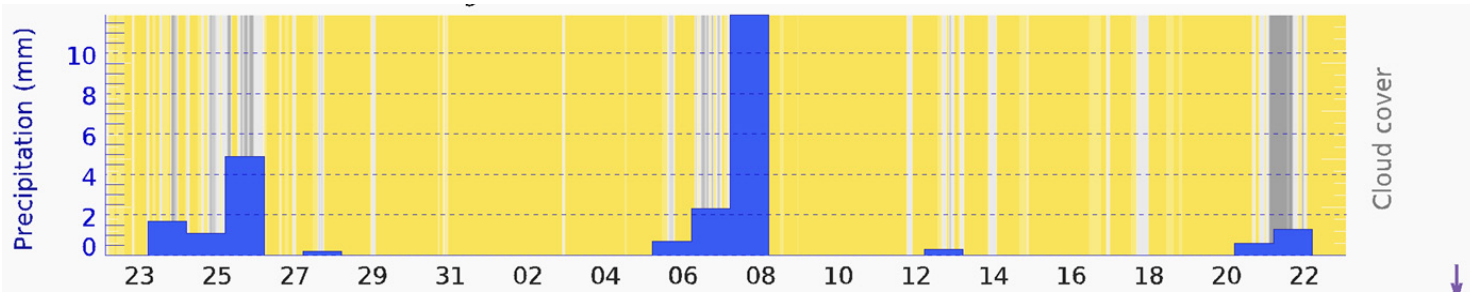

Figure 3. Rainfalls recorded in Chinteni in the year 2017 (Dec. 2016-Aug. 2017)

Romania, located on $16 \mathrm{~km}$ distance of ClujNapoca city. The experimental area is placed on an average altitude of $475 \mathrm{~m}$, generally characterized by favorable climate for the development of forage crops (Fig.1.).

This experiment includes 18 treatments in three replicates, resulting in 54 plots which were combination of two forage plants, namely red clover and Italian ryegrass in mixture and pure stands and in different technological conditions. Experimental design was performed after the randomized complete blocks method - plant were sown in alternate rows on two different densities, namely 12.5 and $25 \mathrm{~cm}$ and were treated with mineral fertilizer in 3 doses: 1 control variant, unfertilized, plot fertilized with N50P60K80, plot fertilized with N100P60K80. Sown was made in the spring of 2016 (14 of April). Fertilization was made each year in spring. Three cuts were taken each year and the current paper presents the amount of this reduction for the year 2017 . Interpretation of data was performed using Statistica vs 10.

\section{Results and discussions}

The climatic data for Chinteni commune recorded in 2017 was favorable for forage species development, with temperatures and humidity close to optimal during the vegetation period (Fig. 2 and 3). Climatic data were downloaded from www.meteoblue.com.

The results pointed out that the highest DM production are achieved in the experimental 


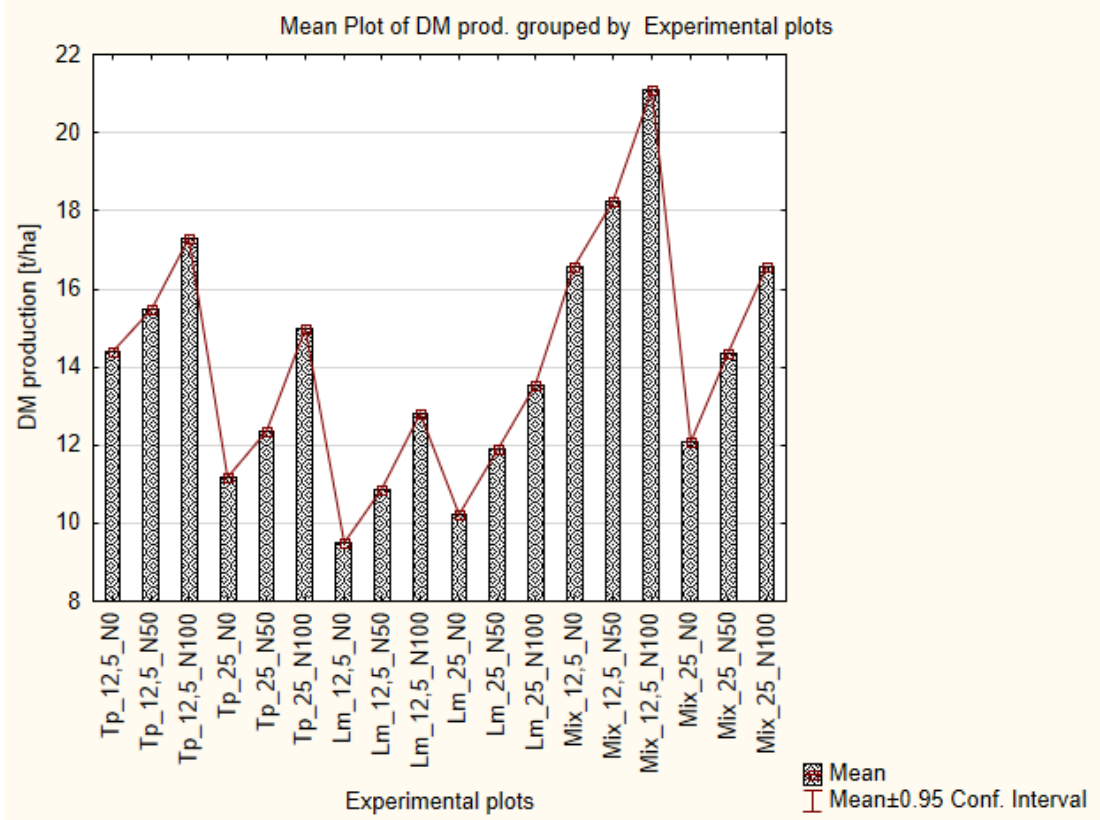

Note: Tp_12,5_N0 - red clover, unfertilized, sown on $12.5 \mathrm{~cm}$; Tp_12,5_N50 - red clover fertilized with N50P60K80, sown on $12.5 \mathrm{~cm}$; Tp_12,5_N100 - red clover fertilized with N100P60K80, sown on $12.5 \mathrm{~cm}$; Tp_25_N0 - red clover, unfertilized, sown on $25 \mathrm{~cm}$; Tp_25_N50 - red clover, fertilized with N50P60K80, sown on $25 \mathrm{~cm}$; Tp_25_N100 - red clover, fertilized with N100P60K80, sown on 25 cm; Lm_12,5_N0 Italian ryegrass, unfertilized, sown on $12.5 \mathrm{~cm}$; Lm_12,5_N50 - Italian ryegrass, fertilized with N50P60K80, sown on 12.5 cm; Lm_12,5_N100

- Italian ryegrass, fertilized with N100P60K80, sown on $12.5 \mathrm{~cm}$; Lm_25_N0 - Italian ryegrass, unfertilized, sown on 25 cm; Lm_25_N50 Italian ryegrass, fertilized with N50P60K80, sown on $25 \mathrm{~cm}$; Lm_25_N100 - Italian ryegrass, fertilized with N100P60K80, sown on $25 \mathrm{~cm}$; Mix_12,5_N0 - mixture, unfertilized, sown on $12.5 \mathrm{~cm}$; Mix_12,5_N50 - mixture fertilized with N50P60K80, sown on 12.5 cm; Mix_12,5_N100 - mixture fertilized with N100P60K80, sown on $12.5 \mathrm{~cm}$; Mix_25_N0 - mixture, unfertilized, sown on $25 \mathrm{~cm}$; Mix_25_N50 - mixture, fertilized with N50P60K80, sown on $25 \mathrm{~cm}$; Mix_25_N100 - mixture, fertilized with N100P60K80, sown on $25 \mathrm{~cm}$.

Figure 4. Dry matter production recorded in the year 2017

Table 1. Correlations between experimental plots with red clover in pure stands

\begin{tabular}{ccccccc}
\hline & Tp_12,5_N0 & Tp_12,5_N50 & Tp_12,5_N100 & Tp_25_N0 & Tp_25_N50 & Tp_25_N100 \\
\hline Tp_12,5_N0 & & 0.984 & 0.299 & 0.747 & 0.680 & 0.762 \\
\hline Tp_12,5_N50 & 0.984 & & 0.460 & 0.851 & 0.797 & 0.863 \\
\hline Tp_12,5_N100 & 0.299 & 0.460 & & 0.857 & 0.902 & 0.845 \\
\hline Tp_25_N0 & 0.747 & 0.851 & 0.857 & & 0.995 & 0.999 \\
\hline Tp_25_N50 & 0.680 & 0.797 & 0.902 & 0.995 & & 0.992 \\
\hline Tp_25_N100 & 0.762 & 0.863 & 0.845 & 0.999 & 0.992 &
\end{tabular}

Note: Tp_12,5_N0 - red clover, unfertilized, sown on $12.5 \mathrm{~cm}$; Tp_12,5_N50 - red clover fertilized with N50P60K80, sown on $12.5 \mathrm{~cm}$ Tp_12,5_N100 - red clover fertilized with N100P60K80, sown on $12.5 \mathrm{~cm}$; Tp_25_N0 - red clover, unfertilized, sown on $25 \mathrm{~cm}$; Tp_25_ N50- red clover, fertilized with N50P60K80, sown on 25 cm; Tp_25_N100 - red clover, fertilized with N100P60K80, sown on $25 \mathrm{~cm}$.

plots sown with mixture formed by red clover and Italian ryegrass despite of the technological conditions applied (Fig. 4.). In this stands DM production between $12 \mathrm{t}$ /ha (Mix_25_N0) and 21 t/ha (Mix_12,5_N100) were recorded. Bozhanska (2017) also pointed out that forage mixture productivity is higher, as each species in the mixture contributes in various degree for the increase of the dry matter yield.

In which concerns the experimental plots in pure stands we observed that red clover responds better to the climatic and technologycal conditions characteristic to the experimental area. Therefore
DM production between $11 \mathrm{t} / \mathrm{ha}$ (Tp_25_N0) and $17 \mathrm{t} /$ ha (Tp_12,5_N100) were recorded in this plots, values much higher than those harvested from the experimental plots sown with Italian ryegrass. There are many other researchers which pointed out the potential of red clover sown either pure or in mixture with a suitable perennial grass, to maintain high output of quality herbage without the aid of fertilizer N (McBratney, 1984; Queen et al., 2009; Georgieva et al., 2015; Kosev, 2015). There are several researchers which highlighted that perennial forage grasses have many valuable qualities, which can be used in obtaining of more 
Table 2. Correlations between experimental plots with Italian ryegrass in pure stands

\begin{tabular}{ccccccc}
\hline & Lm_12,5_N0 & Lm_12,5_N50 & Lm_12,5_N100 & Lm_25_N0 & Lm_25_N50 & Lm_25_N100 \\
\hline Lm_12,5_N0 & & 0.908 & -0.996 & 0.896 & -0.991 & -0.105 \\
\hline Lm_12,5_N50 & 0.908 & & -0.869 & 0.999 & -0.846 & 0.318 \\
\hline Lm_12,5_N100 & -0.996 & -0.869 & & -0.855 & 0.998 & 0.190 \\
\hline Lm_25_N0 & 0.896 & 0.999 & -0.855 & & -0.830 & 0.345 \\
\hline Lm_25_N50 & -0.991 & -0.846 & 0.998 & -0.830 & & 0.235 \\
\hline Lm_25_N100 & -0.105 & 0.318 & 0.190 & 0.345 & 0.235 &
\end{tabular}

Note: Lm_12,5_N0-Italian ryegrass, unfertilized, sown on $12.5 \mathrm{~cm}$; Lm_12,5_N50-Italian ryegrass, fertilized with N50P60K80, sown on $12.5 \mathrm{~cm}$; Lm_12,5_N100- Italian ryegrass, fertilized with N100P60K80, sown on $12.5 \mathrm{~cm}$; Lm_25_N0- Italian ryegrass, unfertilized, sown on $25 \mathrm{~cm}$; Lm_25_N50- Italian ryegrass, fertilized with N50P60K80, sown on $25 \mathrm{~cm}$; Lm_25_N100- Italian ryegrass, fertilized with N100P60K80, sown on $25 \mathrm{~cm}$.

Table 3. Correlations between experimental plots with red clover and Italian ryegrass in mixed stands

\begin{tabular}{ccccccc}
\hline & Mix_12,5_N0 & Mix_12,5_N50 & Mix_12,5_N100 & Mix_25_N0 & Mix_25_N50 & Mix_25_N100 \\
\hline Mix_12,5_N0 & & 0.600 & 0.695 & 0.841 & 0.991 & 0.679 \\
\hline Mix_12,5_N50 & 0.600 & & -0.158 & 0.936 & 0.493 & -0.179 \\
\hline Mix_12,5_N100 & 0.695 & -0.158 & & 0.197 & 0.780 & 0.999 \\
\hline Mix_25_N0 & 0.841 & 0.936 & 0.197 & & 0.766 & 0.175 \\
\hline Mix_25_N50 & 0.991 & 0.493 & 0.780 & 0.766 & & 0.766 \\
\hline Mix_25_N100 & 0.679 & -0.179 & 0.999 & 0.175 & 0.766 & \\
\hline
\end{tabular}

Note: Mix_12,5_N0 - mixture, unfertilized, sown on $12.5 \mathrm{~cm}$; Mix_12,5_N50 - mixture fertilized with N50P60K80, sown on $12.5 \mathrm{~cm}$; Mix_12,5_N100 - mixture fertilized with N100P60K80, sown on 12.5 cm; Mix_25_N0 - mixture, unfertilized, sown on 25 cm; Mix_25_ N50 - mixture, fertilized with N50P60K80, sown on $25 \mathrm{~cm}$; Mix_25_N100 - mixture, fertilized with N100P60K80, sown on $25 \mathrm{~cm}$.

feed for livestock and also that this forage plants are distinguished by high resistance, ecological plasticity, adaptability and energy value of the feed (Zhekova, 2016; Georgieva et al., 2015; Lelièvrea et al., 2011; Kostov and Pavlov, 1999; Pavlov, 1996).

Analysing the influence of feeding space we observed that the highest DM productions were achieved on the experimental plots sown on 12.5 $\mathrm{cm}$ distance between rows, except for Italian ryegrass in pure stands which gaved the highest harvests on this particular density.

The study pointed out that fertilization with N100P60K80 is favorable for this forage plants both in pure stands and in mixture, resulting in increased DM production on all the experimental plotanalyzed. The highest DM harvest was achieved of 21 t/ha was recorded on Mix_12,5_N100, plot fertilized with N100P60K80 and sown on $12.5 \mathrm{~cm}$ between rows. McBratney (1984) demonstrate that following decline in red clover yield may be restored by the application of $\mathrm{N}$ fertilizer, particularly where the clover was seeded with a highly productive companion grass. Høgh-Jensen and Schjoerring (1997) concluded that positive interactions occur between clover and ryegrass growing in mixture ensure a more efficient fixation of atmospheric N2 and absorption of fertilizer $\mathrm{N}$ and soil derived $\mathrm{N}$ than pure stands of the same species.

Statistical analyses highlighted differences recorded between control variant (Tp_25_N0) and Tp_25_N100, variant fertilized with N100P60K80, sown on $25 \mathrm{~cm}$ (Table 1.). Significant differences are kept also between Tp_25_N50 and Tp_25_ $\mathrm{N} 100(\mathrm{p}<0.05)$.

Differences statistically distinguished significant are recorded between Lm_25_N0 and Lm_12.5_N50 and between Lm_12.5_N100 and Lm_25_N50 ( $<<0.01$; Table 2). Significant differences are noticed also between the control plot Lm_12.5_N0 and Lm_12.5_N100 ( $<<0.05)$.

Analysis of the mixture formed by red clover and Italian ryegrass revealed distinguished significant differences between Mix_12.5_N100 and Mix_25_N100 ( $<<0.01$; Table 3). This result highlights the influence of distance between rows on mixture productivity revealing that red clover is very favored by a lower density while Italian ryegrass gives higher productions on a higher density of plants.

The presence of interspecific competition is pointed out thru a lower DM production recorded on control plots compared to treatments, independent of species density (Fig. 5.). The 


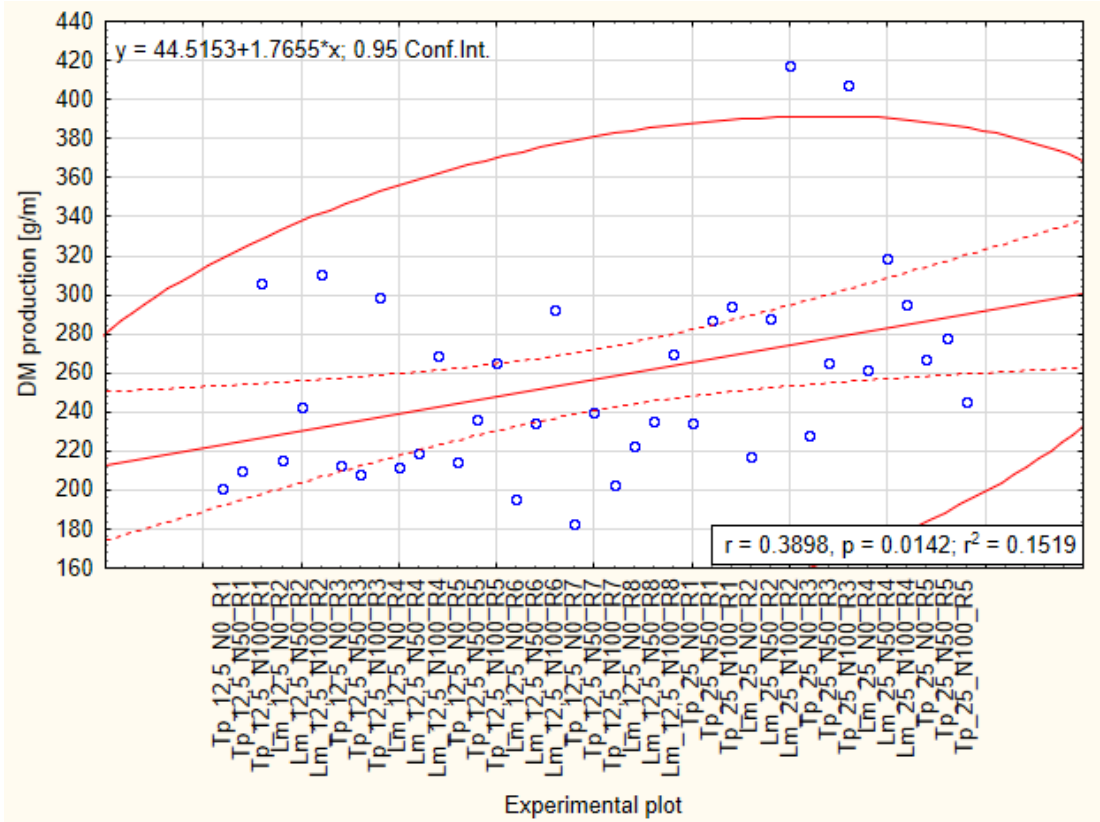

Note: Tp_12,5_N0_R1, Tp_12,5_N0_R3, Tp_12,5_N0_R5, Tp_12,5_N0_R7 - red clover, unfertilized, sown on $12.5 \mathrm{~cm}$ - first (R1), second (R3), third (R5), fourth (R7) row; Tp_12,5_N50_R1, Tp_12,5_N50_R3, Tp_12,5_5_R5, Tp_12,5_N50_R7 - red clover fertilized with N50P60K80, sown on $12.5 \mathrm{~cm}$, first (R1), second (R3), third (R5), fourth (R7) row; Tp_12,5_N100_R1, Tp_12,5_N100_R3, Tp_12,5_N100_R5, Tp_12,5_N100_R7 - red clover fertilized with N100P60K80, sown on $12.5 \mathrm{~cm}$, first (R1), second (R3), third (R5), fourth (R7) row; Tp_25_N0_R1, Tp_25_N0_R3, Tp_25_N0_R5 - red clover, unfertilized, sown on $25 \mathrm{~cm}$ - first (R1), second (R3), third (R5);, Tp_25_N50_R1, Tp_25_N50_R3, Tp_25_N50_R5 red clover fertilized with N50P60K80, sown on $25 \mathrm{~cm}$ - first (R1), second (R3), third (R5); Tp_25_N100_R1, Tp_25_N100_R3, Tp_25_N100_R5 - red clover fertilized with N100P60K80, sown on $25 \mathrm{~cm}$ - first (R1), second (R3), third (R5) row; Lm_12,5_N0_R2, Lm_12,5_N0_R4, Lm_12,5_ N0_R6, Lm_12,5_N0_R8 - Italian ryegrass, unfertilized, sown on $12.5 \mathrm{~cm}$ - first (R2), second (R4), third (R6), fourth (R8) row; Lm_12,5_N50 R2, Lm_12,5_N50_R4, Lm_12,5_N50_R6, Lm_12,5_N50_R8 - Italian ryegrass, fertilized with N50P60K80, sown on $12.5 \mathrm{~cm}$ - first (R2), second (R4), third (R6), fourth row (R8); Lm_12,5_N100_R2, Lm_12,5_N0_R4, Lm_12,5_N100_R6, Lm_12,5_N100_R8 - Italian ryegrass, fertilized with N100P60K80, sown on $12.5 \mathrm{~cm}$ - first (R2), second (R4), third (R6), fourth row (R8); Lm_25_N0_R2, Lm_25_N0_R4 - Italian ryegrass, unfertilized, sown on $25 \mathrm{~cm}$ - first (R2), second (R4) row; Lm_25_N50_R2, Lm_25_N50_R4 - Italian ryegrass, fertilized with N50P60K80, sown on $25 \mathrm{~cm}$ - first (R2), second (R4) row; Lm_25_N100_R2, Lm_25_N100_R4 - Italian ryegrass, fertilized with N100P60K80, sown on 25 $\mathrm{cm}$ - first (R2), second (R4) row.

Figure 5. The influence of experimental factors on DM production $(\mathrm{g} / \mathrm{m})$

release of competition thru fertilization resulted in DM increases on all rows, despite of the species sown. The increase in DM production in line with the increase of nutrient application highlights that soil reserves in chemical elements are not enough for this mixture thus treatments are required for achieving optimum productivity. Similar observations were made also by Vasileva (2015) who pointed out that one of the advantages of using organic fertilizers is releasing more nutrients in root zone of plants.

The highest ability for competition was recorded by red clover which generally gave the highest DM production on all rows sown on 12.5 $\mathrm{cm}$. It seems like Italian ryegrass was favored by the density of $25 \mathrm{~cm}$ where DM production was generally higher on every row compared to that recorded by red clover.

The results showed that this mixture requirements for feeding space were not achieved on $12.5 \mathrm{~cm}$ therefore increasing the feeding space up to $25 \mathrm{~cm}$ is justified since led to increases in DM production/row on both of the studied species.

Statistical processing of data revealed a low correlation between the experimental factors analyzed and DM production/row, pointing out that approximately $16 \%$ of cases follow a common variance while over $80 \%$ of cases have a specific variation.

\section{Conclusion}

Data analysis pointed out that red clover is more productive than Italian ryegrass. The most suitable crop choice for the experimental site analyzed is the mixture formed by red clover and Italian ryegrass which gaved the highest DM production compared to pure stands. As technologycal measures we recommend sowing on $12.5 \mathrm{~cm}$ between rows in adition to fertilization with N100P60K80. 
In which concerns the interspeciffic competition data pointed out that the highest ability for competition was recorded by red clover which generally gaved the highest DM production on all rows sown on $12.5 \mathrm{~cm}$. It seems like Italian ryegrass was favored by the density of $25 \mathrm{~cm}$ where DM production/row was generally higher on every row compared to that recorded by red clover.

\section{References}

1. Archibald S (2008). African grazing lawns - How fire, rainfall, and grazer numbers interact to affect grass community states. Journal Wildlife Manage, 72: 492-501.

2. Bozhanska T (2017). Study on perennial legume-grass mixtures in the conditions of the Central Balkan Mountain. Banats journal of biotechnology, 8(15): 34-42.

3. Fynn R, Morris C, Kirkman K (2005). Plant strategies and trait trade-offs influence trends in competitive ability along gradients of soil fertility and disturbance. Journal Ecol, 93: 384-394.

4. Georgieva N, Pachev I, Katova A, Naydenova Y (2015) Study of introduced varieties of perennial grass species grown in the conditions of Central Northern Bulgaria. Banats journal of biotechnology, 6(12): 20-29.

5. Hamdollah E, Ahmad G, Abdollah J (2009). Intercropping of Cereals and Legumes for Forage Production. Notulae Scientia Biologicae, 1: 7-13.

6. Høgh-Jensen H and JK Schjoerring (1997). Interactions between white clover and ryegrass under contrasting nitrogen availability: N2 fixation, $\mathrm{N}$ fertilizer recovery, $\mathrm{N}$ transfer and water use efficiency. Plant and Soil, 197(2): 187-199.
7. Keeling J, Matches A, Brown C, Karnezos T (1996). Comparison of inter seeded legumes and small grains for cover crop establishment in cotton. Agron. J., 88: 219-222.

8. Kosev VI (2015). Multivariate analysis of spring field pea genotypes. Banats journal of biotechnology, 6(11): 23-29.

9. Kostov K, Pavlov D (1999). Forage production. Academic Pushing House of the Higher Agricultural University, Plovdiv.

10. Le Gall A, Guernion JM (2004). Associations Graminées Trèfle blanc. Le pâturage gagnant, 61-62.

11. Lelièvre F, Seddaiu G, Ledda L, Porqueddu C, Volaire F (2011). Water use efficiency and drought survival in Mediterranean perennial forage grasses. Field Crops Research, 121: 333-342.

12. McBratney JM (1984). Productivity of red clover grown alone and with companion grasses; further studies. Grass and Forage Science, 39.

13. Păcurar F, Rotar I, Vidican R, Vaida I, Mălinaș A, Stoian V (2016). Ecological and agronomical value of Festuca rupicola heuff. Grasslands. Romanian journal of grassland and forage crops, 13: 23-39.

14. Queen A, Hugh E, William D (2009). Light and moisture competition effects on biomass of red clover underseeded to winter wheat. Agron. Journal, 101: 1511-1521.

15. Vasileva V (2015). Root biomass accumulation in vetch (Vicia sativa L.) after treatment with organic fertilizer. Banats journal of biotechnology, 6(11): 100-105.

16. Vidican R, Rotar I, Carlier L (2006). Perspectives of the organic farming in Romania. Bulletin of UASVM, Seria Agriculture, 62: 198-201.

17. Weather in Chinteni, Cluj County, Romania (2017). URL https://www.meteoblue.com/en/weather/forecast/ week/cluj-napoca_romania_681290.

18. Zhekova ED (2016). Entomological monitoring in ecological crop rotation, Banats journal of biotechnology, 7(13): 77-81. 